Article

\title{
Epigenetic Features of Human Perinatal Stem Cells Redefine Their Stemness Potential
}

\author{
Giulia Gaggi ${ }^{1}$, Andrea Di Credico ${ }^{1}$, Pascal Izzicupo ${ }^{1}{ }^{\circledR}$, Ivana Antonucci ${ }^{2}{ }^{\circledR}$, Clara Crescioli ${ }^{3}$,

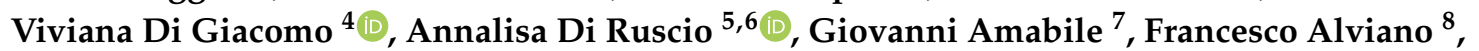 \\ Angela Di Baldassarre ${ }^{1, *,+} \mathbb{D}$ and Barbara Ghinassi ${ }^{1, *,+} \mathbb{D}$ \\ 1 Department of Medicine and Aging Sciences, “G. D'Annunzio" University of Chieti- Pescara, \\ 66100 Chieti, Italy; giulia.gaggi@unich.it (G.G.); andrea.dicredico@unich.it (A.D.C.); izzicupo@unich.it (P.I.) \\ 2 Department of Psychological, Humanities and Territorial Sciences, "G. D'Annunzio" University of Chieti, \\ Pescara, 66100 Chieti, Italy; i.antonucci@unich.it \\ 3 Department of Movement, Human and Health Sciences, University of Rome "Foro Italico", \\ 00135 Rome, Italy; clara.crescioli@uniroma4.it \\ 4 Department of Farmacy, “G. D'Annunzio” University of Chieti- Pescara, 66100 Chieti, Italy; \\ viviana.digiacomo@unich.it \\ 5 Department of Translational Medicine, University of Eastern Piedmont, 28100 Novara, Italy; \\ adirusci@bidmc.harvard.edu \\ 6 Beth Israel Deaconess Medical Center, Harvard Medical School Initiative for RNA Medicine, \\ Harvard Medical School, Boston, MA 02115, USA \\ 7 Enthera Srl, 20123 Milan, Italy; giovanni.amabile@entherapharmaceuticals.com \\ 8 Department of Experimental, Diagnostic and Specialty Medicine, Unit of Histology, Embryology and \\ Applied Biology, University of Bologna, 40126 Bologna, Italy; francesco.alviano@unibo.it \\ * Correspondence: angela.dibaldassarre@unich.it (A.D.B.); b.ghinassi@unich.it (B.G.) \\ + These authors contributed equally.
}

Received: 2 April 2020; Accepted: 22 May 2020; Published: 24 May 2020

\begin{abstract}
Human perinatal stem cells (SCs) can be isolated from fetal annexes without ethical or safety limitations. They are generally considered multipotent; nevertheless, their biological characteristics are still not fully understood. The aim of this study was to investigate the pluripotency potential of human perinatal SCs as compared to human induced pluripotent stem cells (hiPSCs). Despite the low expression of the pluripotent factors NANOG, OCT4, SOX2, and C-KIT in perinatal SC, we observed minor differences in the promoters DNA-methylation profile of these genes with respect to hiPSCs; we also demonstrated that in perinatal SCs miR-145-5p had an inverse trend in comparison to these stemness markers, suggesting that NANOG, OCT4, and SOX2 were regulated at the post-transcriptional level. The reduced expression of stemness markers was also associated with shorter telomere lengths and shift of the oxidative metabolism between hiPSCs and fetal annex-derived cells. Our findings indicate the differentiation ability of perinatal SCs might not be restricted to the mesenchymal lineage due to an epigenetic barrier, but other regulatory mechanisms such as telomere shortening or metabolic changes might impair their differentiation potential and challenge their clinical application.
\end{abstract}

Keywords: perinatal stem cells; amniotic fluid stem cells; amniotic epithelial cells; fetal membrane mesenchymal stromal cells; NANOG; OCT4; SOX2; DNA methylation; miRNAs expression; telomere length

\section{Introduction}

Stem cells (SCs) are undifferentiated and unspecialized cells that have the ability to self-renew and differentiate into specialized cells through asymmetric and symmetric divisions [1]. Human (h) 
SCs are generally divided into four main groups: embryonic SCs (hESCs), induced pluripotent SCs (hiPSCs), perinatal SCs, and adult or somatic SCs. Adult SCs reside in specialized niches within organs during post-natal life; they usually are oligo- or unipotent and are critical for tissue regeneration [2]. hESCs are pluripotent cells that can be isolated from the inner cell mass of the blastocyst; they can differentiate into all embryonic and extra-embryonic tissues [3]; however, their use is impaired by ethical and clinical concerns as their isolation causes the destruction of a blastocyst and they can form teratomas [4]. These ethical problems were overcome when Yamanaka et al. generated hiPSCs from adult human fibroblasts through the retroviral transduction of OCT3/4, SOX2, KLF4, and c-MYC: due to the activity of these factors, differentiated cells can be reprogrammed and returned to a pluripotent state. hiPSCs have a self-renewal capacity, thus representing an unlimited source for research and are quite similar to hESCs in terms of their transcription programs and global chromatin configuration [5]. Despite the high hopes generated by hiPSCs research, the biology of these cells still casts shadows on their clinical application. Technical hurdles in the reprogramming result in a different quality of hiPSCs, the epigenetic memory influences the differentiation efficiency and their biological instability is responsible for poorly controlled risks of unpredictable reactions in patients [6].

Currently, only a few clinical trials have tested the safety of hiPSCs for therapeutic purposes [7]. For this reason, scientists have focused their attention on SCs that can be isolated from human perinatal tissue. Placenta and amniotic fluid represent an interesting source of SCs for clinical and research purposes, as they are easily obtainable and their use does not raise ethical concerns; moreover, they display paracrine activity by secreting cytokines that are involved in angiogenesis, immune modulation, and tissue repair (for a review, see Gaggi et al. [4]). They are generally considered multipotent, nevertheless, their real position in the stemness hierarchy and their differentiative potential remain unclear. Different cell populations can be isolated from fetal annexes.

Human fetal membrane mesenchymal stromal cells (hFM-MSCs) can be isolated from the amniochorionic membrane. They have a fibroblast-like shape and can be expanded in vitro for at least nine passages without changes to the cell morphology [8]. hFM-MSCs can differentiate into mesodermal lineages and have a low immunogenicity, expressing at a very low level the HLA class I and class II antigens on their surface and lack co-stimulatory molecules, such as CD80, CD40, and CD40 ligands [8].

Human amniotic epithelial cells (hAECs), derived from the amniotic membrane, originate from the epiblast at days 8-9 during the development, before gastrulation [9]. They express some markers of pluripotency; however, unlike ESCs, they neither cause teratomas nor activate the immune system after transplantation in vivo. In adhesion, hAECs show the cuboidal morphology of epithelial cells; whereas, in suspension culture, they form an embryoid body structure, a characteristic typical of ESCs [4,9]; however, in vitro they have a low proliferation efficiency, and their survival is limited to five to six passages.

SCs have been also isolated from the amniotic fluid. Human amniotic fluid SCs (hAFSC) can be easily recovered after amniocentesis and are able to differentiate into several cell lineages $[4,10]$. They are not tumorigenic; thus, they represent a good potential candidate for therapeutic applications [11].

Although some features of perinatal SCs support their potential use in regenerative medicine, a more extensive analysis of their biological characteristics is needed prior to encouraging the translation of the preclinical studies into therapy. The aim of this study was to better delineate the stemness features of human perinatal SCs by outlining some of their epigenetic, genetic, and biological characteristics in comparison with hiPSCs.

\section{Materials and Methods}

\subsection{Culture of Human Cells}

All culture mediums and supplements were purchased by Thermo Fisher Scientific (Waltham, MA, USA), unless otherwise indicated. 
The hiPSCs [12] were cultured on a monolayer of irradiated-murine fibroblasts (Thermo Fischer Scientific, Waltham, MA, USA) in Dulbecco's Modified Eagle's Medium/Nutrient Mixture F-12 (DMEM/F12) supplemented with 20\% KnockOut Serum Replacement (KO), 1\% penicillin/streptomycin, $2 \mathrm{mM}$ L-glutamine, $5 \mathrm{ng} / \mathrm{mL}$ basic fibroblast growth factor (bFGF), and 1\% MEM nonessential amino acid.

Placenta and amniotic fluid samples were obtained after written informed consent in accordance with the Declaration of Helsinki. All samples had normal diploid karyotypes. The study was approved by the ethics committees of the "G. d'Annunzio" University of Chieti-Pescara, ASL Lanciano-Chieti-Vasto and of St. Orsola-Malpighi University Hospital, Italy and all experiments were performed in accordance with relevant guidelines and regulations. The hAFSCs were isolated as previously described [13] from 15 women undergoing amniocentesis for prenatal diagnosis at 16-17 weeks of pregnancy; cells were cultured in Iscove's modified Dulbecco's medium (IMDM) supplemented with $20 \%$ fetal bovine serum (FBS), $1 \%$ penicillin/streptomycin, $2 \mathrm{mM}$ L-glutamine, and $5 \mathrm{ng} / \mathrm{mL}$ bFGF. The hFM-MSCs and hAECs were isolated from the term placentas of 6 healthy donors mothers as previously described [14]. Cells were cultured in DMEM 10\% FBS, 1\% penicillin/streptomycin, and $2 \mathrm{mM}$ L-glutamine. For hAECs culture, medium was supplemented with $10 \mathrm{ng} / \mathrm{mL}$ epidermal growth factor (Sigma-Aldrich, Saint Louis, MO, USA). All the cell culture media and supplements are summarized in Table 1.

Table 1. Cell media and supplements.

\begin{tabular}{|c|c|c|c|}
\hline Cell Type & Medium & Supplements & Provider \\
\hline hiPSCs & DMEM F/12 & $\begin{array}{c}20 \% \mathrm{KO} \\
5 \mathrm{ng} / \mathrm{mL} \text { bFGF } \\
1 \% \text { MEM non essential amino acid }\end{array}$ & \multirow{4}{*}{$\begin{array}{l}\text { All the media and supplements } \\
\text { were purchased by Thermo Fishe } \\
\text { Scientific (Waltham, MA, USA) }\end{array}$} \\
\hline hAFSCs & IMDM & $\begin{array}{c}20 \% \text { FBS } \\
5 \mathrm{ng} / \mathrm{mL} \text { bFGF }\end{array}$ & \\
\hline hFM-MSCs & DMEM & $10 \%$ FBS & \\
\hline hAECs & DMEM & $\begin{array}{c}10 \% \text { FBS } \\
10 \mathrm{ng} / \mathrm{mL} \text { EGF }\end{array}$ & \\
\hline
\end{tabular}

All the media were always completed with 1\% penicillin/streptomycin, $2 \mathrm{mM}$ L-glutamine.

All the experiments were performed at early cell passages ( $2-4$ passages).

\subsection{RNA Extraction and Reverse Transcription}

RNA from hESCs was purchased from Celprogen (Torrance, CA, USA). The hiPSCs, hAFSCs, hFM-MSCs, and hAECs were lysed with QIAzol lysis reagent (QIAGEN, Hilden, Germany). The total RNA was extracted using the miRNeasy Mini Kit (QIAGEN, Hilden, Germany) according to the manufacturer's procedure [15]. For reverse transcription, $1 \mu \mathrm{g}$ of RNA was retrotranscribed by the high-capacity cDNA reverse transcription kit (Thermo Fisher Scientific, Waltham, MA, USA) according to the manufacturer's procedure. For the reverse transcription of miRNAs, $1 \mu \mathrm{g}$ of RNA was retrotranscribed using the high-capacity cDNA reverse transcription kit (Thermo Fisher Scientific, Waltham, MA, USA) following the stem and loop reverse transcription (RT) protocol [16]: buffer RT $10 \times 2 \mu \mathrm{L}$, dNTPs $0.8 \mu \mathrm{L}$, U6 RT primer $(10 \mathrm{pmol} / \mu \mathrm{L}) 4 \mu \mathrm{L}$, miR-299-3p RT primer $(10 \mathrm{pmol} / \mu \mathrm{L})$ or miR-150-5p RT primer (10 pmol/ $\mu \mathrm{L}) 4 \mu \mathrm{L}$, or miR-145-5p RT primer (10 pmol/ $\mu \mathrm{L})$, MultiScribe ${ }^{\mathrm{TM}} 2 \mu \mathrm{L}$, and $\mathrm{H}_{2} \mathrm{O} 15 \mu \mathrm{L}$. The primers used for the experiments are summarized in Table 2.

Table 2. The primers for the stem and loop reverse transcription (RT) protocol.

\begin{tabular}{cr}
\hline \multicolumn{1}{c}{ miRNA } & Sequence $\mathbf{( 5}^{\prime}-\mathbf{3}^{\prime} \mathbf{)}$ \\
\hline miR_299-3p_RT & GTCGTATCCAGTGCAGGGTCCGAGGTATTCGCACTGGATACGACAAGCGG \\
\hline miR_145-5p_RT & GTCGTATCCAGTGCAGGGTCCGAGGTATTCGCACTGGATACGACAGGGAT \\
\hline miR_150-5p_RT & GTCGTATCCAGTGCAGGGTCCGAGGTATTCGCACTGGATACGACCACTGG \\
\hline miR_U6_RT & GAACGCTTCACGAATTTGCGTGTCAT \\
\hline
\end{tabular}




\subsection{Real Time Quantitative PCR ( $q P C R$ )}

For all the examined mRNAs, qPCR analysis was performed using SYBR green (PowerUp SYBR Green Master mix, Thermo Fisher Scientific, Waltham, MA, USA) in a final volume of $20 \mu \mathrm{L}$. The samples were analyzed in triplicate in MicroAmp optical 96-well reaction plates (Thermo Fisher Scientific, Waltham, MA, USA). Since normalization to GAPDH has been shown to be not very accurate [17], the more stable $18 \mathrm{~S}$ was used as a housekeeping gene. Two different mixes were initially prepared to be subsequently distributed with a 1:1 ratio in each well. We mixed SYBR green-primers $(10 \mu \mathrm{L} /$ well): SYBR green $9.2 \mu \mathrm{L}$, mixed primers FW $+\mathrm{RV}(10 \mathrm{pmol} / \mu \mathrm{L}) 0.8 \mu \mathrm{L}$. Then mixed cDNA-RNase free water (10 $\mu \mathrm{L} /$ well): cDNA (12.5 ng/well) $2 \mu \mathrm{L}$, and RNase free water $8 \mu \mathrm{L}$. The samples were run as follows: step $1,95{ }^{\circ} \mathrm{C}$ for $10 \mathrm{~min}$; step $2,95^{\circ} \mathrm{C}$ for $15 \mathrm{~s}$; and step $3,60^{\circ} \mathrm{C}$ for $1 \mathrm{~min}$. Steps 2 and 3 were repeated for 40 cycles. The authenticity of the PCR products was verified by a melt-curve analysis. For data analysis, the $\mathrm{Ct}$ value of all genes analyzed was normalized to the $\mathrm{Ct}$ of the housekeeping gene 18S, resulting in the $\Delta \mathrm{Ct}$ value. Next, the $\Delta \Delta \mathrm{Ct}$ value was obtained subtracting the $\Delta \mathrm{Ct}$ value of each experimental condition from $\Delta \mathrm{Ct}$ value of the control condition (hESC). Finally, the fold change was generated using the formula $2^{-\Delta \Delta C t}$.

To detect the miR-299-3p, miR-150-5p, and miR-145-5p, qPCR was performed as previously described, but with using $U 6$ as a housekeeping gene and $25 \mathrm{ng}$ of cDNA per reaction. For data analysis, the $\Delta \Delta \mathrm{Ct}$ method was used with hiPSCs as a control condition. The primers used are listed in Table 3.

Table 3. The primers for real time PCR.

\begin{tabular}{cc}
\hline Gene & Sequence $\mathbf{( 5}^{\prime} \mathbf{- 3}^{\prime} \mathbf{)}$ \\
\hline NANOG-FW & CCAGACCCAGAACATCCAGTC \\
\hline NANOG-RW & CACTGGCAGGAGAATTTGGC \\
\hline Endo-OCT4-FW [18] & GGGTTTTTGGGATTAAGTTCTTCA \\
\hline Endo-OCT4-RW [18] & GCCCCCACCCTTTGTGTT \\
\hline Endo-SOX2-FW [18] & CAAAAATGGCCATGCAGGTT \\
\hline Endo-SOX2-RW [18] & AGTTGGGATCGAACAAAAGCTATT \\
\hline c-kit-FW & CCACACCCTGTTCACTCCTT \\
\hline c-kit-RW & TTCTGGGAAACTCCCATTTGTG \\
\hline 18S-FW [19] & CATGGCCGTTCTTAGTTGGT \\
\hline 18S-RW [19] & CGCTGAGCCAGTCAGTGTAG \\
\hline miR-299-3p_FW & CGTGGAGTATGTGGGATGGTAAA \\
\hline mir-150-5p_FW & GCATGTCTCCCAACCCTTGTA \\
\hline miR-145-5p_FW & GAAGGTCCAGTTTTCCCAGGA \\
\hline miR_universal_RW & GTGCAGGGTCCGAGGT \\
\hline miR_U6_FW & CTCGCTTCGGCAGCACA \\
\hline miR_U6_RW & AACGCTTCACGAATTTGCGT \\
\hline
\end{tabular}

\subsection{MTT (3[4,5-Dimethylthiazol-2yl]-2,5-Diphenyl Tetrazolium Bromide) Assay}

The cell metabolic activity was measured using a MTT (3[4,5-dimethylthiazol-2yl]-2,5-diphenyl tetrazolium bromide) growth assay (Sigma-Aldrich, Saint Louis, MO, USA). The cells were seeded at $15.625 \mathrm{cell} / \mathrm{cm}^{2}$ and after $24 \mathrm{~h}$ treated with $0.5 \mathrm{mg} / \mathrm{mL}$ MTT for $4 \mathrm{~h}$. After incubation, formazan, generated by MTT reduction, was solubilized in dimethyl sulfoxide (DMSO) for 30 min at $37^{\circ} \mathrm{C}$. The absorbance of each well was detected at $540 \mathrm{~nm}$. 


\subsection{Flow Cytometry}

For flow cytometry, the cells were treated with the FIX and PERM ${ }^{\circledR}$ Kit (Thermo Fisher Scientific, Waltham, MA, USA) and then incubated for $1 \mathrm{~h}$ at room temperature with anti-Oct- 4 Alexa Fluor 488 conjugated (Cell Signaling, Danvers, MA, USA) 1:50, anti-Nanog Alexa Fluor 647 conjugated (Becton Dickinson, Franklin Lakes, NJ, USA) 1:20, anti-c-Kit PE conjugated (Becton Dickinson, Franklin Lakes, NJ, USA) 1:5, anti-Sox2 Alexa Fluor 488 conjugated (Becton Dickinson, Franklin Lakes, NJ, USA) 1:5 or appropriate isotype controls [20] (all from Becton Dickinson, NJ, USA). Cytometric analyses were performed with a Cytoflex cytometer (Beckman Coulter, Brea, CA, USA), and the data were analyzed with CytExpert Acquisition and Analysis Software (Beckman Coulter, Brea, CA, USA).

\subsection{Immunofluorescent Analysis}

For the immunofluorescence, the cells were treated as previously reported [21,22]. The samples were incubated with anti-Oct-4 Alexa Fluor 488 conjugated (Cell Signaling, Danvers, MA, USA) 1:50, anti-Nanog Alexa Fluor 488 conjugated (Becton Dickinson, Franklin Lakes, NJ, USA) 1:5, anti-c-Kit PE conjugated (Becton Dickinson, Franklin Lakes, NJ, USA) 1:5, and anti-Sox2 Alexa Fluor 488 conjugated (Becton Dickinson, Franklin Lakes, NJ, USA) 1:5. The nuclei were stained with DAPI (Thermo Fisher Scientific, Waltham MA, USA). The images were acquired with Camera Axiocam 503 Mono and analyzed with ZEN Software (Carl Zeiss, Jena, Germany).

\subsection{Pyrosequencing}

Genomic DNA was extracted from hiPSCs, hMFs, hAECs, and hAFSCs using the blood and cell culture mini kit (QIAGEN, Hilden, Germany) and quantified by Qubit 4 (Thermo Fisher Scientific, Waltham, MA, USA) according to the manufacturer's instructions. We used $100 \mathrm{ng}$ of genomic DNA in the bisulfite conversion reactions using the EZ DNA methylation direct kit (Zymo Research, Irvine, CA, USA) according to the manufacturer's instructions. The bisulfite-treated samples were then amplified by PCR (SimpliAmp, ThermoFisher Scientific, Waltham, MA, USA), using forward and reverse primers (see Table 3 for PCR primers and conditions), with one primer biotinylated. The bisulfite-converted DNA was amplified with the KAPA HiFi HotStart Uracil + Ready Mix PCR kit (Kapa Biosystems, Roche, Basilea, Switzerland). The amplification cycles included: denaturation (at $95^{\circ} \mathrm{C}$ for $3 \mathrm{~min}$ ), 30 cycles of denaturation $\left(98^{\circ} \mathrm{C}\right.$ for $20 \mathrm{~s}$ ), annealing ( $15 \mathrm{~s}$; annealing temperatures are reported in Table 4$)$, and extension $\left(72{ }^{\circ} \mathrm{C}\right.$ for $\left.1 \mathrm{~min}\right)$, followed by 1 cycle of final extension $\left(72{ }^{\circ} \mathrm{C}\right.$ for $1 \mathrm{~min}$ ). The PCR products were bound to Streptavidin Sepharose HP (Diatech phrarmacogenetics, Jesi, Italy), and captured using the PyroMark ${ }^{\circledR}$ Q96 vacuum preparation tool (Qiagen, Hilden, Germany). After washes, the biotinylated single stranded PCR products were then released into a 96-well format plate (Pyro ID plate, Diatech pharmacogenetics, Jesi, Italy) containing $2 \mu \mathrm{L}$ of 100 pmol pyrosequencing primer suspended in $38 \mu \mathrm{L}$ of annealing buffer. The plate was loaded into the PyroMark ${ }^{\circledR}$ Q96 instrument (Qiagen, Hilden, Germany) and analyzed using the PyroMark ${ }^{\circledR}$ Q96 software for CpG methylation quantitation. The percentage of methylation was expressed for each DNA locus as \%5-mC divided by the sum of methylated and unmethylated cytosines. 
Table 4. Primer for pyrosequencing

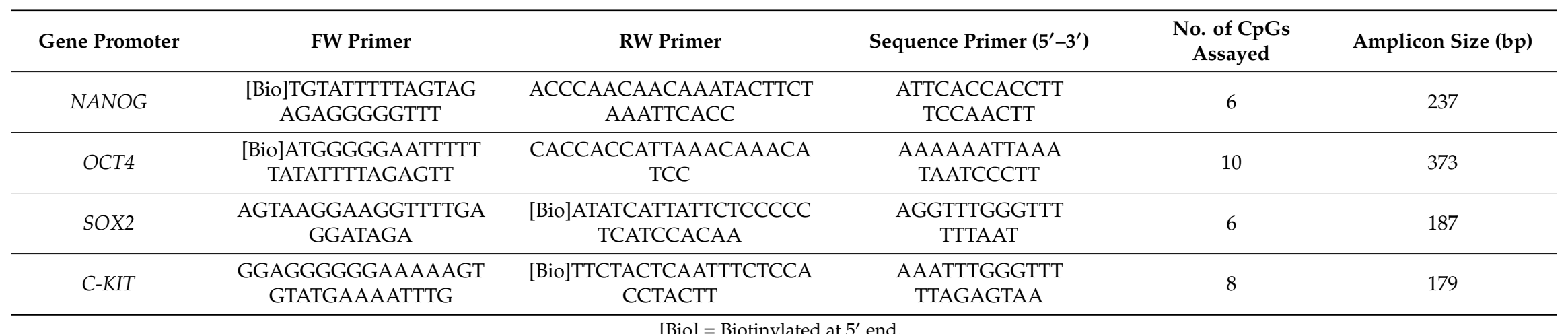




\subsection{Absolute Telomere Length Quantification}

DNA was extracted from hiPSCs, hFM-MSCs, hAECs, and hAFSCs using the blood and cell culture mini kit (QIAGEN, Hilden, Germany), quantified by Qubit 4 (Thermo Fisher Scientific, Waltham, MA, USA) and then analyzed by the absolute human telomere length quantification qPCR assay kit (ScienCell, Carlsbad, CA, USA) according to the manufacturer's instructions. The telomere length per each chromosome end (in $\mathrm{kb}$ ) was calculated using a reference genomic DNA sample with a telomere length per each chromosome end of $7.70 \pm 0.57 \mathrm{~kb}$. To calculate the telomere length for each sample, a reference genomic DNA sample was used.

\subsection{Statistical Analysis}

All data are presented as the mean \pm SD of 5 independent experiments. A statistical analysis was performed using the one-way analysis of variance (ANOVA) and Tukey's post-hoc analysis. The level of significance was set at $p<0.05$.

\section{Results}

\subsection{Promoter DNA Methylation Profile of Stemness Gene in Perinatal SCS}

During the differentiation process, DNA methylation plays an important role in silencing pluripotency-related genes by inhibiting the binding of transcription factors or by recruiting proteins involved in gene repression [23]. It is well known that NANOG, OCT4, and SOX2 represent the triad of master transcription factors of pluripotency [24]. For this reason, we investigated the DNA methylation profile of these transcription factors and C-KIT, another stemness marker expressed in ESCs and other types of SCs [25-27]. The analysis of the methylation levels was carried out by the pyrosequencing of CpGs within the promoters of NANOG, OCT4, SOX2, and C-KIT.

Due to the legal issues related to the manipulation of hESCs in our country, we used hiPSCs as a positive control for our study, knowing that the DNA methylation levels at the promoter of these pluripotent factors is low or undetectable [28,29]. For NANOG, six CpGs were studied: the results indicated that the NANOG methylation levels were comparable between hiPSCs and hFM-MSCs, while they were higher relative to the hiPSCs in hAFSCs and hAEC (Figure 1a).

The pyrosequencing of ten CpGs inside the OCT4 promoter did not demonstrate significant differences in the methylation status between hiPSCs and the SCs isolated from the different placental parts. Among the perinatal SCs, the percentage of OCT4 methylation in hAECs was significantly lower than in hFM-MSCs (Figure 1b).

The investigation of six CpGs into the SOX2 promoter highlighted an important hypomethylation for hiPSCs in comparison with hAFSCs, hAECs and hFM-MSC. Among the perinatal SCs, hAFSC showed significantly lower SOX2 methylation levels than hFM-MSCs and hAECs (Figure 1c).

Finally, pyrosequencing of eight CpGs inside the $c$-KIT promoter displayed a significant lower percentage of DNA methylation in hiPSCs than in fetal annex-derived SCs. Specifically, hAFSCs were characterized by the highest methylation level, while the hAECs by the lowest (Figure 1d).

These data demonstrate that the master genes of pluripotency are hypomethylated in hiPSCs when compared to perinatal SCs. Remarkably the percentage of the OCT4 DNA methylation promoter was similar among all the different SC populations analyzed, and even in NANOG the levels of DNA methylation were very similar between hiPSCs and hFM-MSCs; in addition, perinatal SCs isolated from fetal cells showed a different epigenetic profile with diverse methylation statuses of the stemness marker genes. 


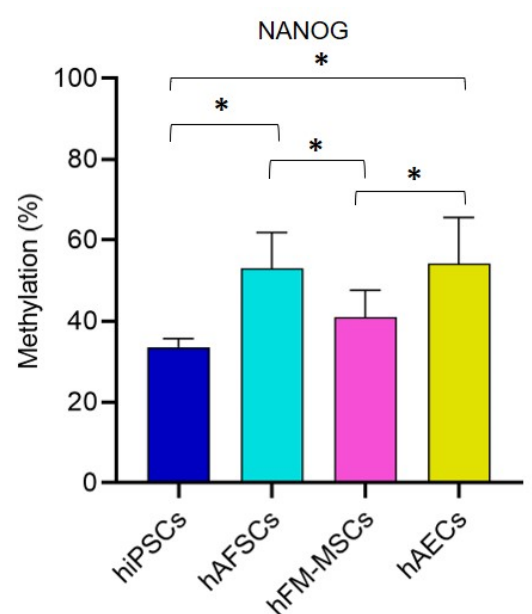

(a)

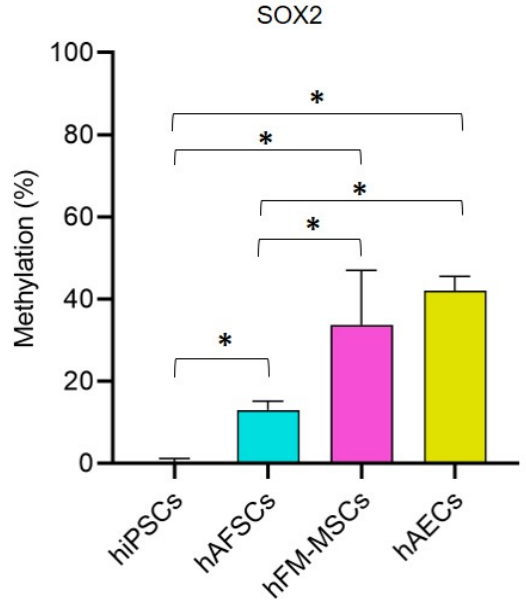

(c)

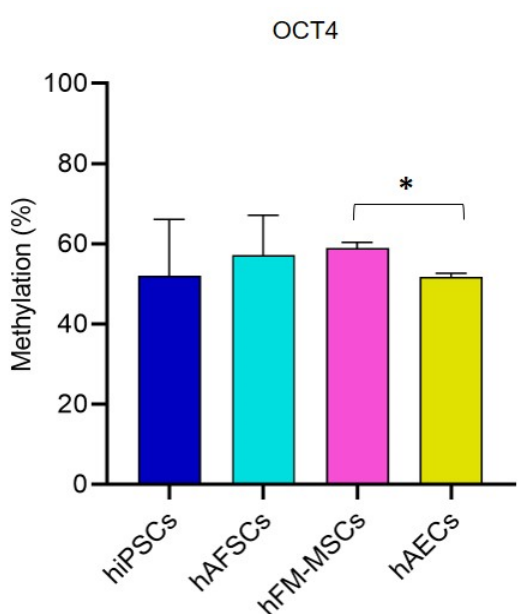

(b)

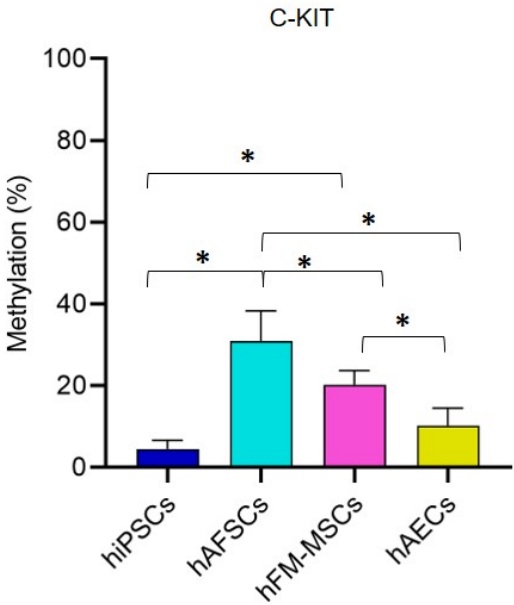

(d)

Figure 1. The methylation profile of NANOG, OCT4, SOX2, and C-KIT in hiPSCs and perinatal stem cells (SCs). Pyrosequencing results showed the percentage of methylation levels in the promoter region of (a) NANOG, (b) OCT4, (c) SOX2, and (d) C-KIT in SCs from different sources. The graphs show the mean \pm SD of 5 independent experiments, ${ }^{*} p<0.05$.

\subsection{Analysis of Pluripotency Gene and Protein Expression in hiPSCs and Human Perinatal SCs}

To assess whether the changes in the DNA methylation profile mirrored the expression of the pluripotent factors we assessed gene expression of NANOG, OCT4, SOX2, and C-KIT by performing quantitative real time PCR on RNA obtained from the different SCs populations. Unexpectedly, perinatal SCs displayed significantly lower mRNA levels of pluripotency markers than hiPSCs, with the exception of $C$-KIT, that was barely detectable in all the tested cells (Figure 2).

We then completed the analysis of the pluripotency markers by analyzing their protein expression and localization by means of cytometric and immunofluorescence analyses. The data are shown in Figures 3 and 4. Despite a comparable percentage of NANOG $^{+}$cells in both hiPSCs and fetal annex-derived SCs, the protein expression measured by the mean fluorescence intensity (MFI) deeply varied from very high (in hiPSCs) to low (in hFM-MSCs) levels. The immunofluorescence analysis confirmed this heterogeneity in the expression levels: while NANOG in the hiPSCs displayed mainly a nuclear localization, as demonstrated by the strong corresponding staining, and suggesting an active state of this transcription factor; hAECs showed weaker immunoreactivity, still maintaining the nuclear 
distribution, contrariwise a fainter fluorescence at both the nuclear and cytoplasmic compartments was observed in hAFSCs and hFM-MSCs.

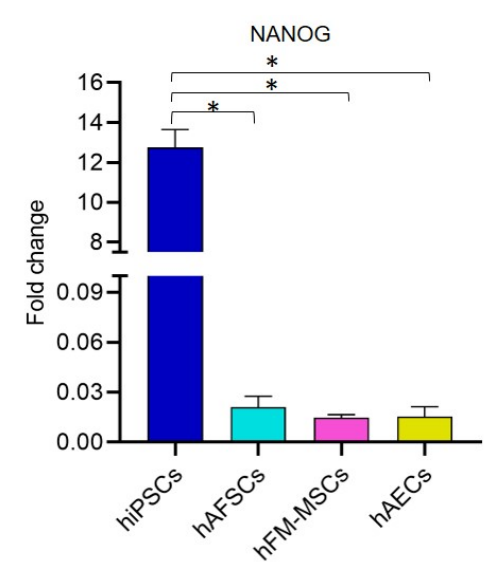

(a)

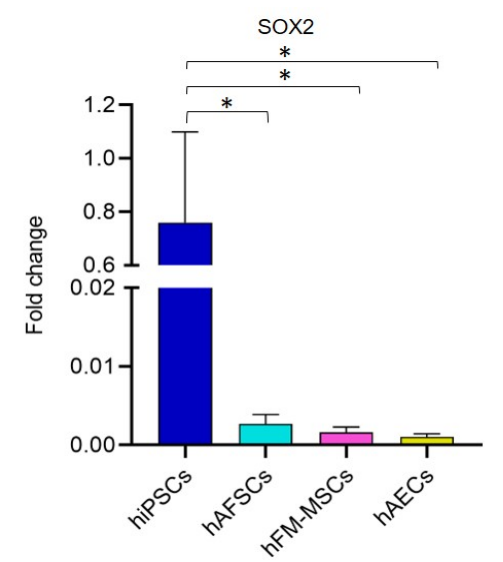

(c)

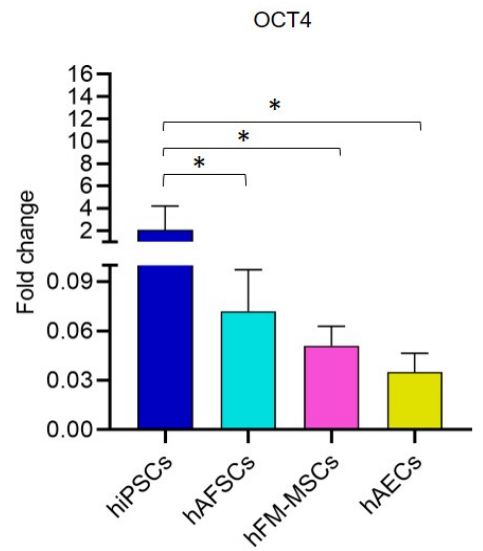

(b)

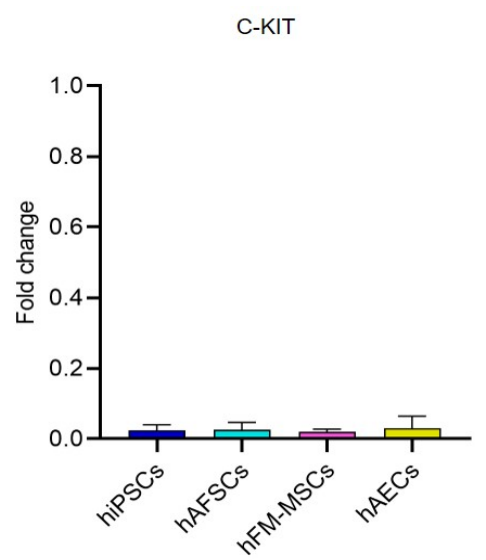

(d)

Figure 2. The gene expression analysis for "stemness genes" in hiPSCs and perinatal SCs. The gene expression of (a) NANOG, (b) OCT4, (c) SOX2, and (d) C-KIT detected by real time PCR in SCs from different sources. The fold changes were determined from the $-\Delta \Delta \mathrm{Ct}$ values calculated using $18 S$ as a reference gene and normalized to hESCs, as the control condition. The graphs show the mean \pm SD of 5 independent experiments, ${ }^{*} p<0.05$.

As expected OCT4 displayed higher levels of both positive cells and MFI values in hiPSCs. Differences in the OCT4 expression levels among the perinatal SCs were also demonstrated. These data were confirmed by the immunofluorescence: as for NANOG, OCT4 showed a stronger nuclear staining in hiPSCs and hAECs, whereas hAFSCs and hFM-MSCs were characterized by a weaker positivity distributed both in the cytoplasmatic and nuclear compartments.

The cytometric analysis for SOX2 evidenced significant differences among the different SCs populations. The immunofluorescence analysis demonstrated a strong nuclear localization in hiPSCs, hAFSCs, and hAECs, whereas in hFM-MSCs the fluorescence clearly marked the cytoplasm. On the contrary, C-KIT was weakly expressed only by a low percentage of hiPSCs $(13.7 \% \pm 0.4 \%)$, being almost undetectable in hAFSCs, hFM-MSCs, and in hAECs.

Our results indicate that the gene and protein expression were generally lower in perinatal SCs in comparison to hiPSCs, even though the NANOG protein expression levels were comparable between hiPSCs, hAFSCs, and hAECs. 

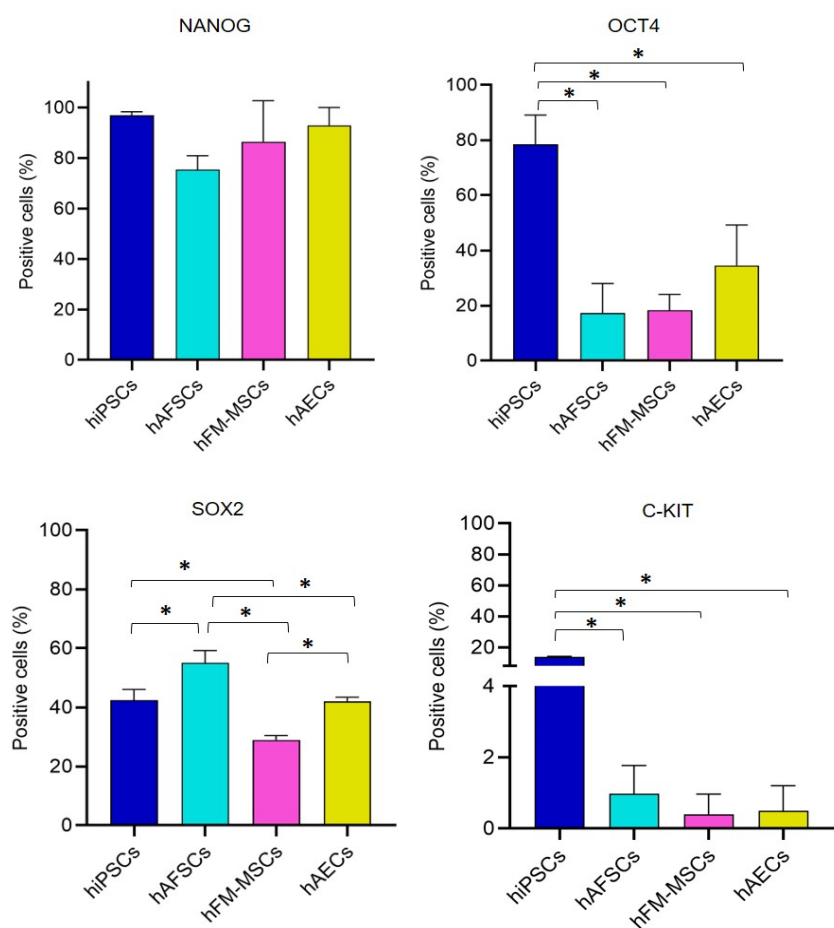

(a)

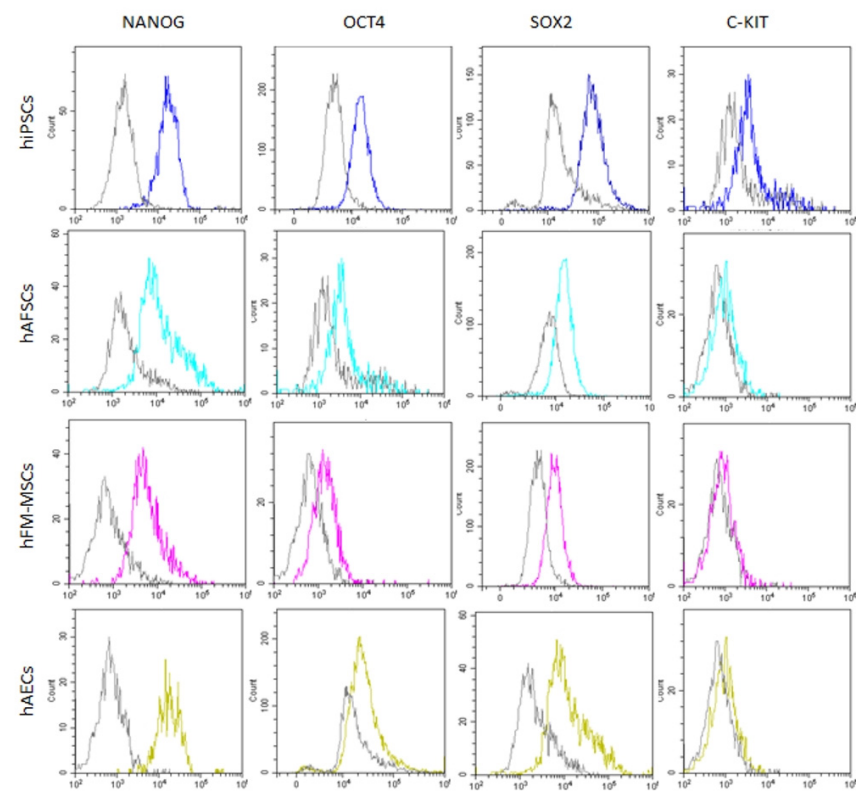

(b)

Figure 3. Protein expression of NANOG, OCT4, SOX2, and C-KIT by a flow cytometry analysis in hiPSCs and perinatal SCs. (a) Graph bars show the percentage of NANOG, OCT4, SOX2, and C-KIT positive cells in hiPSCs and perinatal SCs, obtained by flow cytometry. The graphs show the mean \pm SD of 5 independent experiments, ${ }^{*} p<0.05$. (b) Representative flow cytometry histograms of NANOG, OCT4, SOX2, and C-KIT in hiPSCs and perinatal SCs, as indicated. Grey histograms represent the isotype controls. 


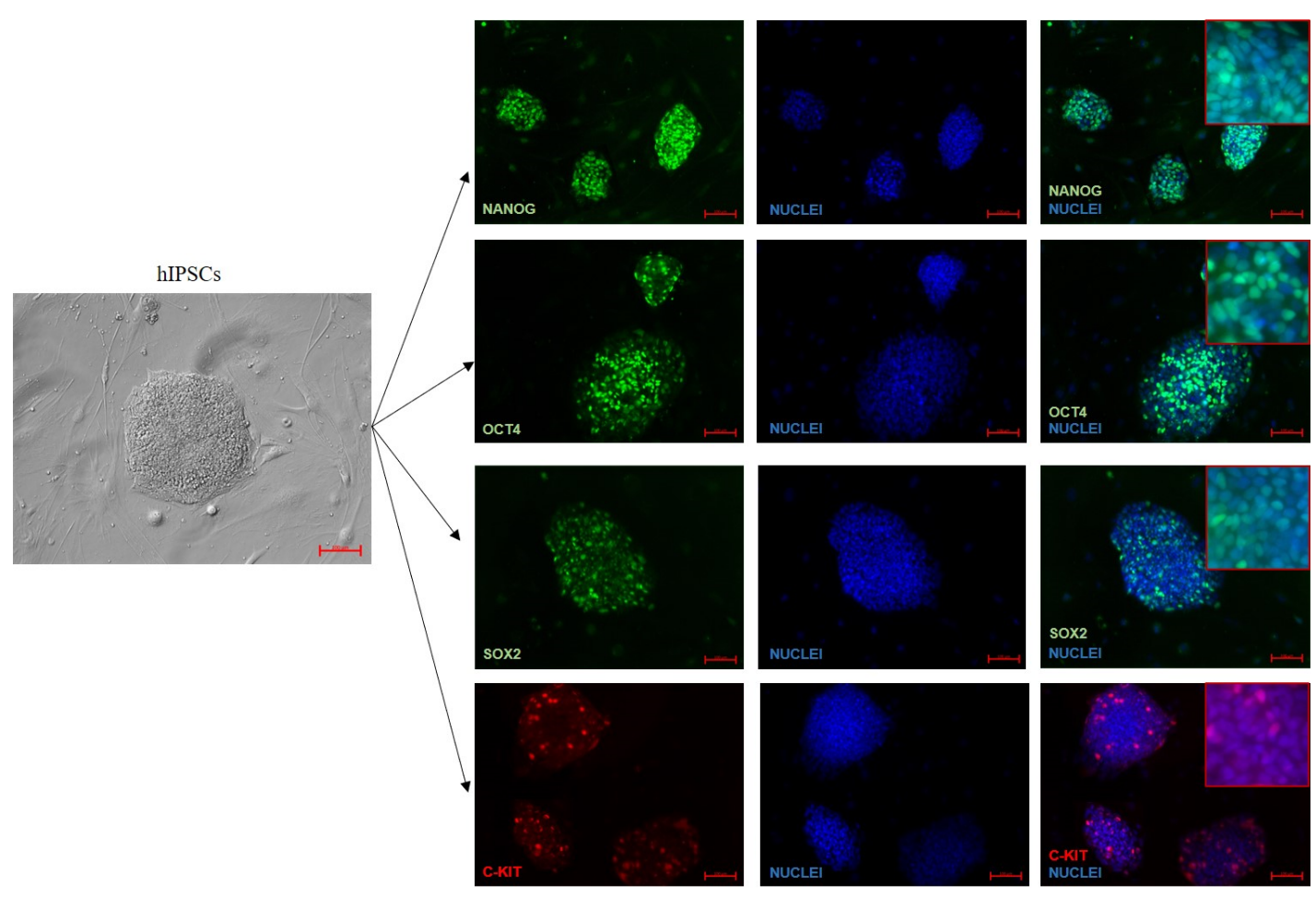

(a)

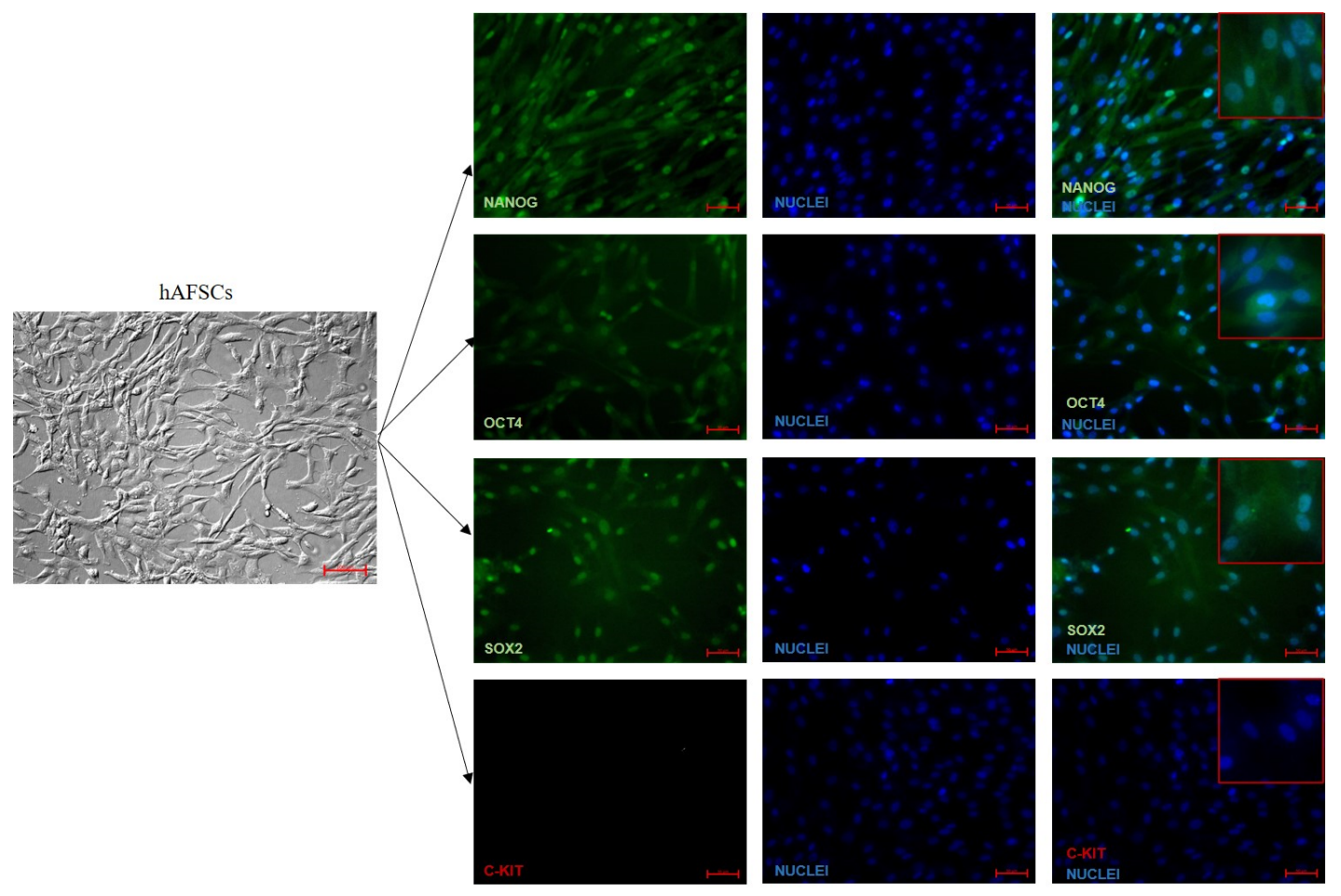

(b)

Figure 4. Cont. 


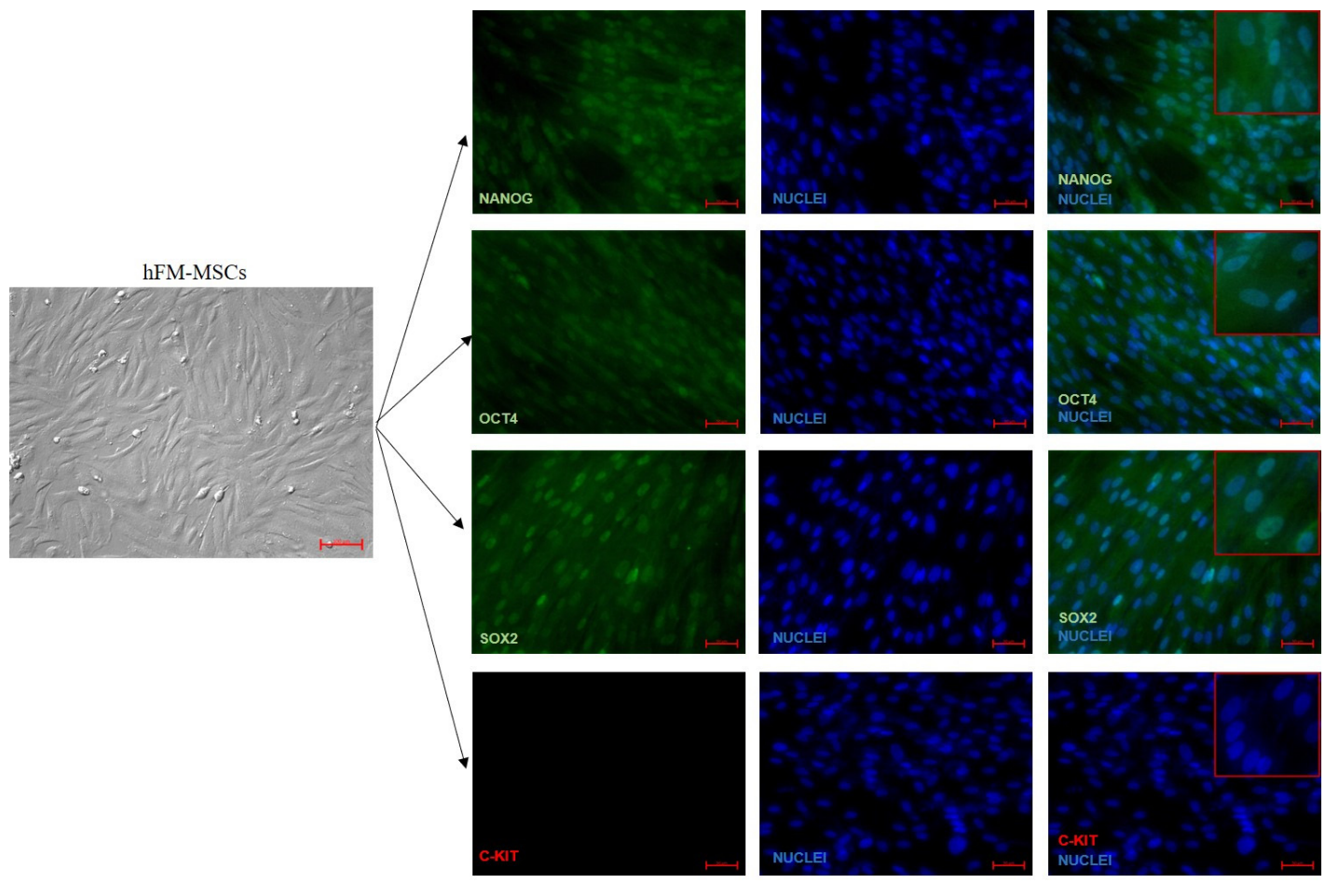

(c)

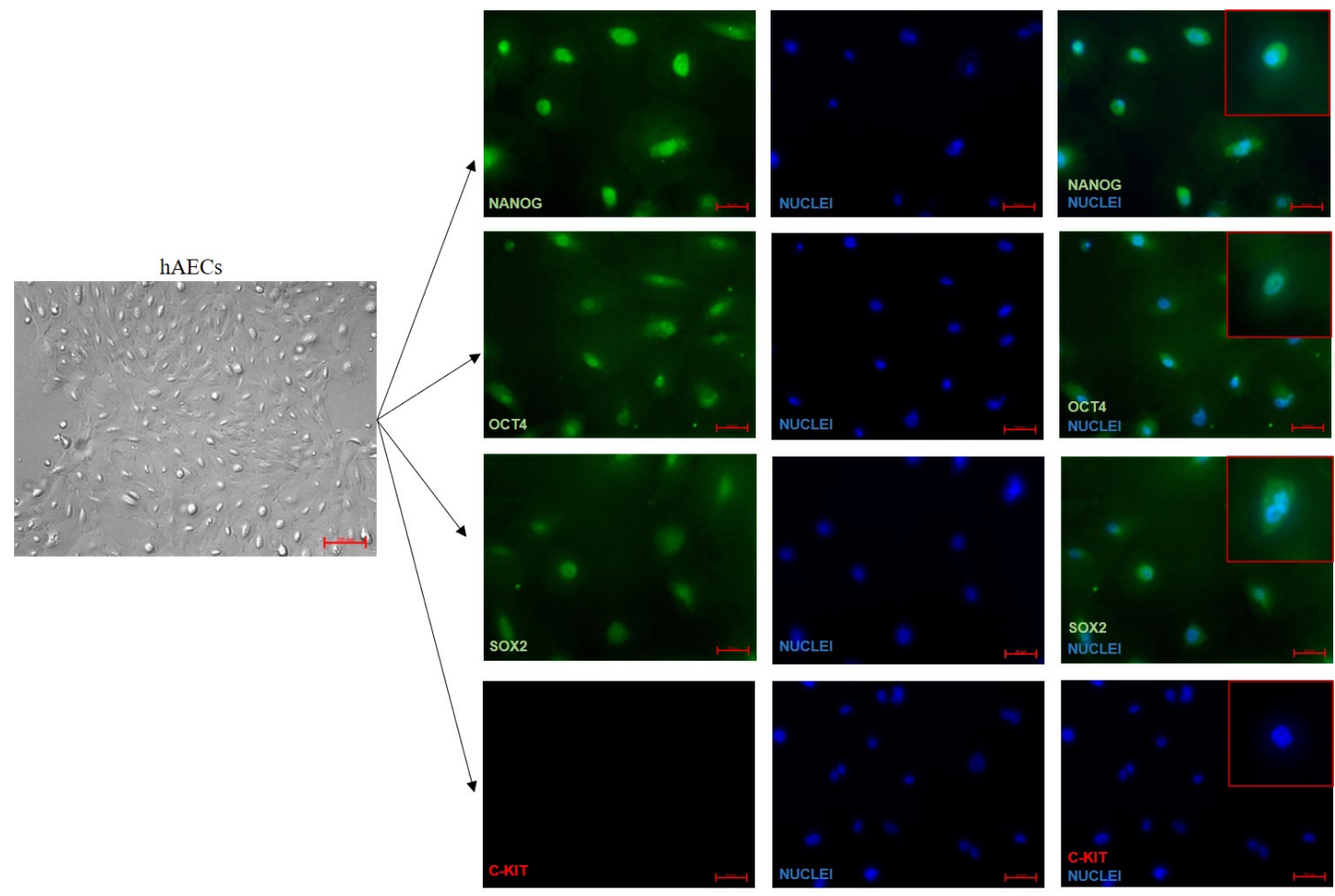

(d)

Figure 4. Immunofluorescent analysis for the NANOG, OCT4, SOX2, and C-KIT expression in hiPSCs and perinatal SCs. NANOG, OCT4, SOX2 (green fluorescence), and C-KIT (red fluorescence) detection in (a) hiPSCs, (b) human amniotic fluid SCs (hAFSCs), (c) fetal membrane mesenchymal stromal cells (hFM-MSCs), and (d) human amniotic epithelial cells (hAECs). The nuclei were counterstained with DAPI (blue). Brightfield images (in grey) highlight the different morphology of the cell populations. The cells were observed with AxioVert A1 using plasDIC-plan neofluar. Original Magnification: brightfield: 10x; Fluorescence: 20x; inset: 40×. Scale bars: brightfield images: $100 \mu \mathrm{m}$; fluorescence images: $50 \mu \mathrm{m}$. The images are representative of 5 independent experiments. 


\subsection{Perinatal SCS Expressed miRNAs That Are Involved in the Regulation of the "Stemness" Gene}

We showed that a similar epigenetic profile between hiPSCs and perinatal SCs is in striking contrast to transcriptional and protein levels of the respective factors. Thus, we investigated the potential involvement of post-transcriptional microRNA-mediated mechanisms to explain this apparent discrepancy. Expression levels of human SCs miR-145-5p that downregulates the overall triad of the pluripotent factors, miR-150-5p and miR-299-3p, known to affect NANOG and OCT4 expression respectively [30-33] were assessed in human perinatal SCs and compared to those in hiPSCs.

Our analyses revealed that among the different SCs populations, the hFM-MSCs expressed significantly higher levels of miR-145-5p (fold change $21.4 \pm 8.5$ ) compared to hAFSCs and hAECs (fold change $1.96 \pm 1.18$ and $1.35 \pm 2.15$, respectively). The expression of NANOG, OCT4, and SOX2, measured as the MFI of the cytometric analysis, displayed an opposite trend to that of miR-145-5p, with hFM-MSCs characterized by the lowest and hiPSCs by the highest levels of protein expression of these stemness markers (Figure 5a).
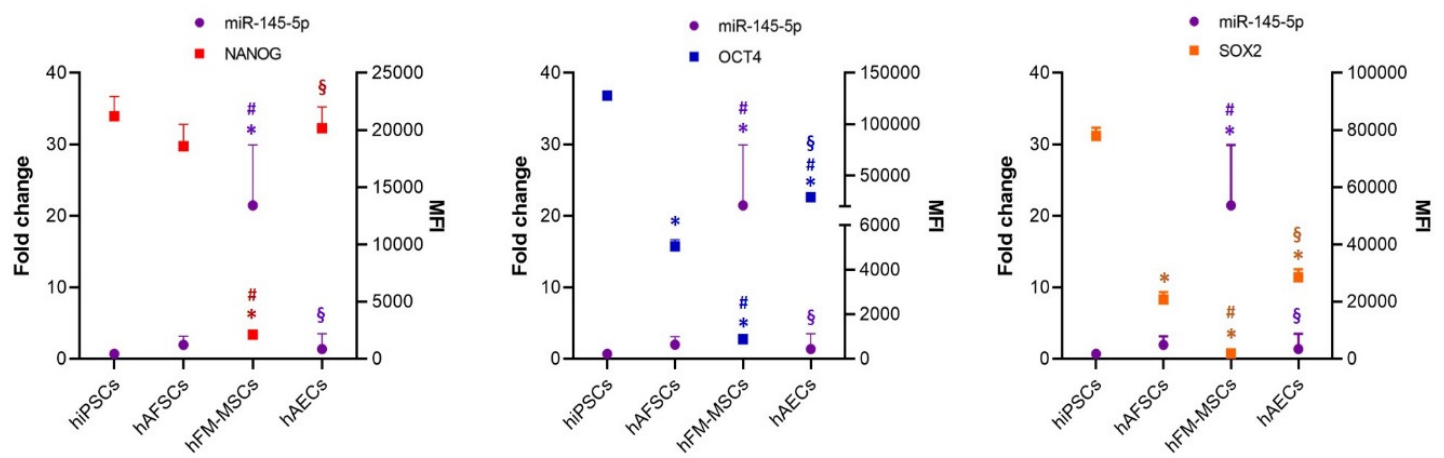

(a)

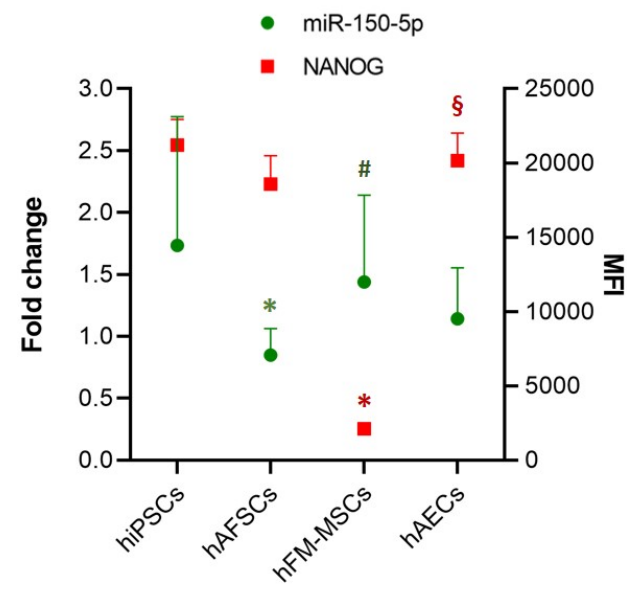

(b)

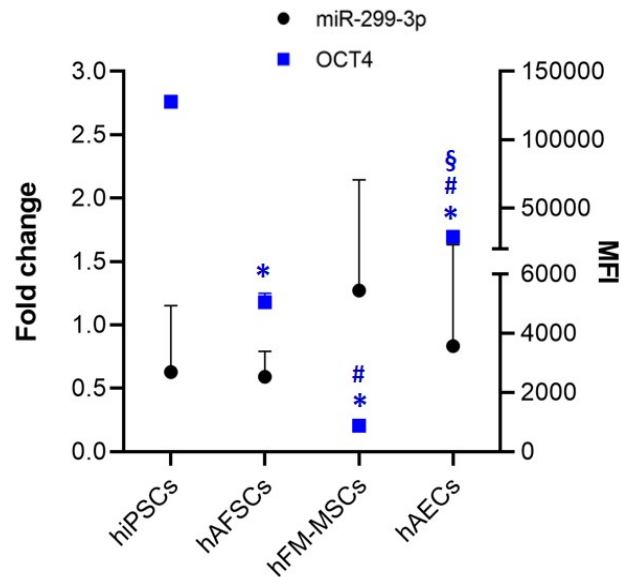

(c)

Figure 5. The detection of miR-299-3p, miR-150-5p, and miR-145-5p in hiPSCs and perinatal SCs and their relationship with the protein expression of NANOG, OCT4, and SOX2. The graph shows the (a) miR-145-5p expression, (b) miR-150-5p, and (c) miR-299-3p (primary y axis) and the expression of the NANOG, OCT4, and SOX2 proteins, as measured with the mean fluorescence intensity by the immunocytometry analysis (secondary y axis) in SCs from different fetal annexes. The miRNAs were detected by real time PCR, the fold change was determined from the $-\Delta \Delta \mathrm{Ct}$ values, calculated using $U 6$ as reference gene and normalized to hiPSCs, as the control condition. The graphs show the mean \pm SD of 5 independent experiments, $p<0.05$ with hiPSCs $\left({ }^{*}\right)$, hAFSCs (\#), and hFM-MSCs (§). 
hAFSCs displayed significantly lower levels of miR-150-5p with respect to hiPSCs, while hFM-MSCs and hAECs expressed comparable levels of this miRNA (Figure 5b). No relationship was observed in the trend of the miR-150-5p expression and the NANOG protein; however, hFM-MSCs showed significant differences of both miR-150-5p and NANOG profiles from hAFSCs.

Finally, the miR-299-3p expression level was compared between hiPSCs and perinatal SCs; only a trend of inverse correlation without reaching the statistical significance between the miRNA and OCT4 expression was observed (Figure 5c).

These results suggest that miRNAs, in particular miR-145-5p, may contribute to the different expression profiles of pluripotency triad proteins in perinatal SCs.

\subsection{Telomere Length Quantification in hiPSCs and Perinatal SCs}

In embryonic SCs, telomerase is activated maintaining the telomere length and cellular immortality; however, the level of telomerase activity seems to be low in the majority of SCs. As it is commonly known that telomeres shorten with aging, thus limiting the proliferative capacity of adult SCs, we performed an absolute quantification of telomere length in perinatal SCs at the second or third passage in comparison with hiPSCs. These cells have been suggested to have telomere lengths that are significantly longer than the parental differentiated cells, reaching a length comparable to ESCs [34]. Our data demonstrated that telomere length is statistically higher in hiPSCs as compared to hAFSCs, hFM-MSCs, and hAECs ( $12 \pm 0.61 \mathrm{~kb}$ vs. $6.1 \pm 1.4 \mathrm{~kb}, 2.9 \pm 0.25 \mathrm{~kb}$, and $3.2 \pm 0.38 \mathrm{~kb}$, respectively). Interestingly, hAFSCs displayed longer telomeres than hFM-MSCs and hAECs suggesting a higher stemness potential. No differences were found between hFM-MSCs and hAECs (Figure 6).

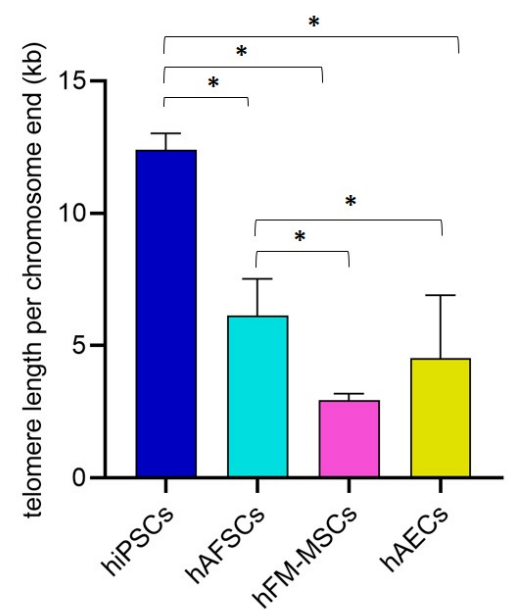

Figure 6. The telomere length per each chromosome end (in $\mathrm{kb}$ ) in hiPSCs and perinatal SCs was quantified by qPCR. All the cells were at $2-4$ passages. The graphs show the mean \pm SD of 5 independent experiments, ${ }^{*} p<0.05$.

\subsection{Metabolic Activity in hiPSCs and Perinatal SCs}

It is well known that the cellular metabolism describes a defined biochemical phenotype of the cells and that it plays a pivotal role in the maintenance of stemness and generation of differentiated progenies [35,36].

Thus, to complete the characterization of the perinatal SCs, we assessed the metabolic activity of the hiPSCs and perinatal SCs by an MTT assay $24 \mathrm{~h}$ after the seeding. The test showed that the metabolism of hAFSCs and hAECs was comparable to the hiPSCs one, while the hFM-MSCs were significantly even more metabolically active than the other perinatal SCs and hiPSCs (Figure 7). 


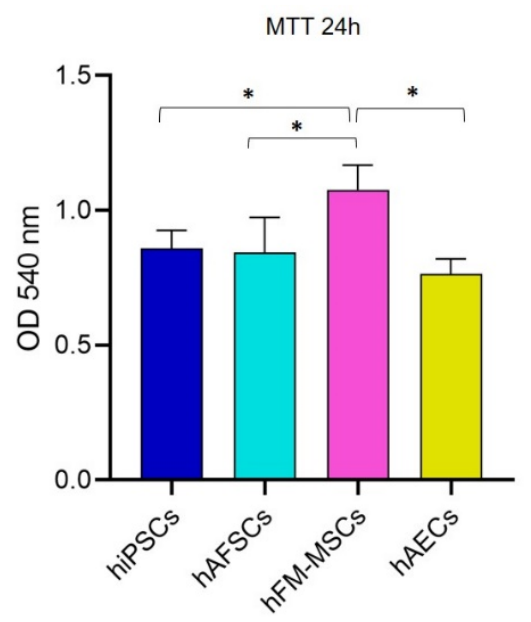

Figure 7. MTT assay for hiPSCs, hAFSCs, hFM-MSCs, and hAECs. The cells were seeded at $15.625 \mathrm{cell} / \mathrm{cm}^{2}$ and after $24 \mathrm{~h}$ they were treated with $0.5 \mathrm{mg} / \mathrm{mL}$ MTT for $4 \mathrm{~h}$. The absorbance is expressed as measure of cell viability and their basal metabolism. The graphs show the mean \pm SD of 5 independent experiments, ${ }^{*} p<0.05$.

\section{Discussion}

In the field of regenerative medicine, the highest differentiation efficiency is obtained from ESCs and iPSCs, but their use in clinical practice is controversial, as they can be tumorigenic. Moreover, the use of ESCs has also ethical limitations as their isolation involves the destruction of a blastocyst [37]. On the other hand, the technical hurdles in reprogramming can affect the quality and the efficiency of iPSC generation; thus, reprogrammed cells can have poorly controlled, unpredictable reactions during clinical applications [6]. Perinatal SCs can be easily isolated during routine medical procedures (amniocentesis) or from fetal annexes after delivery. Evidence suggests that these cells are not tumorigenic and have a low immunogenicity [4]. These properties make AFSCs, FM-MSCs, and AECs a good alternative to ESC and iPSCs in regenerative medicine applications.

SCs from human perinatal tissue cannot divide indefinitely in vitro and are generally considered to be multipotent as they are able to differentiate into various subtypes of the mesodermal lineage. Nevertheless, their biological characteristics and their real position in the stemness hierarchy is still unclear. We have already reported, indeed, that hAFSCs expressed mRNAs of pluripotent markers including NANOG, OCT4, SOX2, FRAGILIS, and KLF4 [13]; moreover it was demonstrated that hAECs express markers typical of glial and neuron cells [38] and can differentiate into cells belonging to different germinal layers, such as cardiac, pancreatic, and hepatic-like cells $[4,10]$. Despite these results, no definitive experiments have been provided for the analysis of "stemness features" of different populations of perinatal SCs.

In our study we attempted to delineate some biological characteristics of the SCs derived from the different parts of the fetal annexes. The main findings of this study are that: $i$. Fetal annex-derived SCs expressed detectable levels of pluripotency markers. ii. Although they showed distinct protein levels, the NANOG, OCT4, and SOX2 genes displayed a similar epigenetic profile in perinatal SCs and hiPSCs. iii. Their downregulation in placenta-derived SCs may be at least in part operated at the post-transcriptional level by specific miRNAs.

The "core circuitry" of pluripotency consists of the homeodomain transcription factors, NANOG, OCT4, and SOX2 in both mouse and human ES cells. These three nuclear factors, closely interacting inside the cell, precisely govern the pluripotent state by regulating a wide range of genes associated with pluripotency signaling networks, including KLF4, C-MYC, TBX3, and ESRRB [39], and by influencing the TGF- $\beta$ and WNT pathways [40]. Several lines of evidence indicated that, in ESCs, small modifications of their complex interplay may affect the pluripotent status: Sox 2 expression 
oscillations, for example, induced multilineage differentiation [41] while blockades of Nanog expression increased their capacity for differentiation into primitive ectoderm cells [42].

The complex C-KIT ligand/C-KIT receptor promoted self-renewal and proliferation in different types of SCs (e.g., embryonal, hemopoietic, and neural SCs) [43].

DNA methylation at the CG dinucleotide in the promoter region of a gene is an epigenetic modification generally associated with gene silencing [44]. Several laboratories have described the epigenetic profile of these pluripotency markers in ESC and iPSCs [5,45], demonstrating that they are hypomethylated in ESCs and that their methylation increases when ESCs begin to differentiate [46]. hiPSCs are similar to ESCs in terms of global chromatin configuration and transcription [5]. Little research is instead available on the epigenetic features of the stemness triad and C-KIT in fetal annex-derived SCs. Our study demonstrates that as compared to hiPSCs, SOX2 and C-KIT promoters were hypermethylated in all perinatal SCs, whereas NANOG was hypermethylated only in hAFSCs and hAECs. The OCT4 methylation level was comparable in hiPSCs and perinatal SCs, and the NANOG methylation profile was similar in hiPSCs and hFM-MSCs. This observation suggests that placenta derived SCs share some epigenetic features with the pluripotent SCs. Despite this epigenetic similarity, the gene and protein expression of OCT4, SOX2, and NANOG differ among the various SC populations, suggesting that other mechanisms are implicated in the transcriptional regulation of these stemness genes such as histone modifications and non-CpG methylation, but further investigations are needed.

Data from flow cytometry and immunofluorescence demonstrated that the protein expression of the pluripotent markers was significantly lower in perinatal SCs relative to iPSCs. For this reason, we also analyzed the expression of miR-299-3p, miR150-5p, and miR145-5p, which are known to be regulators of NANOG, OCT4, and SOX2 [30-33]. Our results demonstrated that perinatal SCs generally expressed higher levels of miRNAs known to interfere with the translation of the triad of pluripotency proteins. Although we did not find a statistical correlation, the trend of expression of miR-145-5p was found to be inverse to that of the NANOG, OCT4, and SOX2 proteins. Thus, these data suggest that this miRNA might be involved in the control of the translation of the core of the self-renewal network, but further functional experiments are needed to specifically address this question.

The transcription factors NANOG, OCT4, and SOX2 after the synthesis may migrate into the nucleus to regulate the downstream transcriptional activity of genes related to the pluripotent status. Their subcellular localization in the nuclear or cytoplasmic compartments can be affected by several cellular and molecular elements or by the cell progression in the stemness hierarchy [47]. SOX2 plays its fundamental role in the maintenance of the pluripotency acting predominately at the nucleus level, as demonstrated by its preferential nuclear localization in hiPSCs [48]. OCT4 is present in the nucleus of the ESCs and in the cytoplasm of downstream cells, such as hematopoietic SCs. This evidence suggests that OCT4 localization may be a hierarchic indicator of the stemness [47]. NANOG has been shown to be localized to both the nucleus and cytoplasm, and its functionalities may depend on its subcellular localization. In our experiments, NANOG, OCT4, and SOX2 were clearly detectable, even if at different extents, in the nuclei of the different perinatal SCs. As the nuclear localization of these transcription factors represents an indicator of stemness, this finding suggests that perinatal SCs may be considered early SCs.

Mammalian telomeres are heterochromatic structures at the end of the chromosomes, consisting of repeats of the TTAGGG sequence, which provide chromosomal stability. Somatic cells are characterized by low levels of telomerase, a reverse transcriptase that extends the telomeric repeats, so that the telomere length progressively shortens with cell divisions and triggers cellular senescence. This progressive telomere shortening is one of the molecular mechanisms that underlie ageing, as critically short telomeres trigger chromosome senescence and loss of cell viability. The telomerase activity and the telomere length of the various SC populations are thus important biological characteristics that must be taken into account in cell-based therapeutic strategies. In ESCs telomerase maintains the telomere length and, as a consequence, their proliferative potential; however, in the majority of SCs, 
the telomerase activity is low regardless of their proliferative capacity, and telomere shortening occurs. Accordingly, our data demonstrated that the telomere length of the perinatal SCs was significantly shorter than that of hiPSCs. Among the various placental derived SCs, the hAFSCs were characterized by significantly longer telomeres.

Telomere length correlated with the developmental pluripotency of ESCs and hiPSCs [49]. ESCs with short telomeres showed a reduction of their teratoma formation capacity and chimera production; moreover, NANOG was expressed at low levels in hESCs with short telomeres, whereas OCT4 and SOX2 expression did not differ in relation to telomere length [50]. According to these data, our study showed that hFM-MSCs have shorter telomeres than hiPSCs and hAFSCs and also lower levels of NANOG expression. Differently, hAECs, although they express high levels of NANOG, are characterized by short telomeres in comparison to hiPSCs and hAFSCs. This is likely the reason for their poor proliferation rate; indeed hAECs can be maintained in culture only for five to six passages [51].

Cellular metabolism describes the biochemical phenotype of the cell. Increasing evidence has demonstrated that the maintenance of stemness and the generation of differentiated lineages are conditioned by cellular metabolism; in particular, a proper quality control of mitochondrial function represents a key factor in SC maintenance and commitment by regulating the redox state [35,36,52]. The bioreduction of water-soluble tetrazolium salts in the MTT assay is generally regarded as an indicator of the cell "redox activity" of the mitochondrial enzymes and electron carriers. Our data demonstrated that perinatal stem cell population analyzed had a comparable, or even higher, "redox activity" to hiPSCs, suggesting that fetal annexes-derived cells, always consider multipotent, might have metabolic features similar to the pluripotent stem cells.

\section{Conclusions}

In conclusion, we found that in perinatal SCs, the pluripotent markers NANOG, OCT4, and SOX2 were not fully silenced, as their promoters were only partially methylated and their expression was regulated at the post transcriptional levels; therefore, the potential of fetal annex-derived SCs might be not restricted to the mesenchymal lineage. While the differentiation properties of the perinatal SCs could be enhanced through a fine-tuned manipulation, the telomere shortening might be the factor limiting their clinical applications in regenerative medicine.

Author Contributions: Conceptualization, A.D.B. and B.G.; Investigation, G.G., A.D.C., P.I., I.A., C.C. and V.D.G.; Methodology, G.G., A.D.C., P.I., I.A., C.C., V.D.G. and F.A.; Supervision, A.D.B. and B.G.; Writing-original draft, G.G. and A.D.B.; Writing-review and editing, A.D.R., G.A., A.D.B. and B.G. All authors have read and agreed to the published version of the manuscript.

Funding: This work was supported by the Italian Ministry of Education, University and Research (Ministero dell'Istruzione, dell'Università e della Ricerca-MIUR), grant numbers SIR2014-RBSI140GLQ and PRIN 2017ATZ2YK. A.D.R was supported by the National Cancer Institute of the National Institutes of Health under Award Number R00CA188595 (the content is solely the responsibility of the authors and does not necessarily represent the official views of the National Institutes of Health); Fondazione Cariplo N. 2016-0476 and the Italian Association for Cancer Research (AIRC) Start-up Grant N.15347.

Conflicts of Interest: The authors declare no conflict of interest.

\section{References}

1. Bieback, K. Critical Parameters for the Isolation of Mesenchymal Stem Cells from Umbilical Cord Blood. Stem Cells 2004, 22, 625-634. [CrossRef] [PubMed]

2. Prentice, D.A. Adult Stem Cells: Successful Standard for Regenerative Medicine. Circ. Res. 2019, 124, 837-839. [CrossRef] [PubMed]

3. Ilancheran, S.; Moodley, Y.; Manuelpillai, U. Human Fetal Membranes: A Source of Stem Cells for Tissue Regeneration and Repair? Placenta 2009, 30, 2-10. [CrossRef] [PubMed]

4. Gaggi, G.; Izzicupo, P.; di Credico, A.; Sancilio, S.; di Baldassarre, A.; Ghinassi, B. Spare Parts from Discarded Materials: Fetal Annexes in Regenerative Medicine. Int. J. Mol. Sci. 2019, 20, 1573. [CrossRef] [PubMed] 
5. Liang, G.; Zhang, Y. Embryonic stem cell and induced pluripotent stem cell: An epigenetic perspective. Cell Res. 2013, 23, 49-69. [CrossRef] [PubMed]

6. Di Baldassarre, A.; Cimetta, E.; Bollini, S.; Gaggi, G.; Ghinassi, B. Human-Induced Pluripotent Stem Cell Technology and Cardiomyocyte Generation: Progress and Clinical Applications. Cells 2018, 7, 48. [CrossRef]

7. Ilic, D.; Polak, J.M. Stem cells in regenerative medicine: Introduction. Br. Med. Bull. 2011, 98, 117-126. [CrossRef]

8. Kmiecik, G.; Niklińska, W.; Kuć, P.; Pancewicz-Wojtkiewicz, J.; Fil, D.; Karwowska, A.; Karczewski, J.; Mackiewicz, Z. Fetal membranes as a source of stem cells. Adv. Med. Sci. 2013, 58, 185-195. [CrossRef]

9. Okere, B.; Alviano, F.; Costa, R.; Quaglino, D.; Ricci, F.; Dominici, M.; Paolucci, P.; Bonsi, L.; Iughetti, L. In vitro differentiation of human amniotic epithelial cells into insulin-producing 3D spheroids. Int. J. Immunopathol. Pharmacol. 2015, 28, 390-402. [CrossRef]

10. Di Baldassarre, A.; D'Amico, M.A.; Izzicupo, P.; Gaggi, G.; Guarnieri, S.; Mariggiò, M.A.; Antonucci, I.; Corneo, B.; Sirabella, D.; Stuppia, L.; et al. Cardiomyocytes Derived from Human CardiopoieticAmniotic Fluids. Sci. Rep. 2018, 8. [CrossRef]

11. Rodrigues, M.; Antonucci, I.; Elabd, S.; Kancherla, S.; Marchisio, M.; Blattner, C.; Stuppia, L. p53 Is Active in Human Amniotic Fluid Stem Cells. Stem Cells Dev. 2018, 27, 1507-1517. [CrossRef] [PubMed]

12. Amabile, G.; Welner, R.S.; Nombela-Arrieta, C.; D'Alise, A.M.; Di Ruscio, A.; Ebralidze, A.K.; Kraytsberg, Y.; Ye, M.; Kocher, O.; Neuberg, D.S.; et al. In vivo generation of transplantable human hematopoietic cells from induced pluripotent stem cells. Blood 2013, 121, 1255-1264. [CrossRef] [PubMed]

13. Antonucci, I.; Di Pietro, R.; Alfonsi, M.; Centurione, M.A.; Centurione, L.; Sancilio, S.; Pelagatti, F.; D’amico, M.A.; Di Baldassarre, A.; Piattelli, A.; et al. Human Second Trimester Amniotic Fluid Cells are Able to Create Embryoid Body-Like Structures in Vitro and to Show Typical Expression Profiles of Embryonic and Primordial Germ Cells. Cell Transplant. 2014, 23, 1501-1515. [CrossRef] [PubMed]

14. Chatgilialoglu, A.; Rossi, M.; Alviano, F.; Poggi, P.; Zannini, C.; Marchionni, C.; Ricci, F.; Tazzari, P.L.; Taglioli, V.; Calder, P.C.; et al. Restored in vivo-like membrane lipidomics positively influence in vitro features of cultured mesenchymal stromal/stem cells derived from human placenta. Stem Cell Res. Ther. 2017, 8. [CrossRef] [PubMed]

15. Di Mauro, M.; Izzicupo, P.; Santarelli, F.; Falone, S.; Pennelli, A.; Amicarelli, F.; Calafiore, A.M.; Di Baldassarre, A.; Gallina, S. ACE and AGTR1 Polymorphisms and Left Ventricular Hypertrophy in Endurance Athletes. Med. Sci. Sports Exerc. 2010, 42, 915-921. [CrossRef] [PubMed]

16. Chen, C. Real-time quantification of microRNAs by stem-loop RT-PCR. Nucleic Acids Res. 2005, 33 , e179. [CrossRef]

17. Mannelli, M.; Ferruzzi, P.; Luciani, P.; Crescioli, C.; Buci, L.; Corona, G.; Serio, M.; Peri, A. Cushing's Syndrome in a Patient with Bilateral Macronodular Adrenal Hyperplasia Responding to Cisapride: An in Vivo and in Vitro Study. J. Clin. Endocrinol. Metab. 2003, 88, 4616-4622. [CrossRef]

18. Aasen, T.; Raya, A.; Barrero, M.J.; Garreta, E.; Consiglio, A.; Gonzalez, F.; Vassena, R.; Bilić, J.; Pekarik, V.; Tiscornia, G.; et al. Efficient and rapid generation of induced pluripotent stem cells from human keratinocytes. Nat. Biotechnol. 2008, 26, 1276-1284. [CrossRef]

19. Jiang, Y.; Jakovcevski, M.; Bharadwaj, R.; Connor, C.; Schroeder, F.A.; Lin, C.L.; Straubhaar, J.; Martin, G.; Akbarian, S. Setdb1 Histone Methyltransferase Regulates Mood-Related Behaviors and Expression of the NMDA Receptor Subunit NR2B. J. Neurosci. 2010, 30, 7152-7167. [CrossRef]

20. Ghinassi, B.; Ferro, L.; Masiello, F.; Tirelli, V.; Sanchez, M.; Migliaccio, G.; Whitsett, C.; Kachala, S.; Riviere, I.; Sadelain, M.; et al. Recovery and Biodistribution of Ex Vivo Expanded Human Erythroblasts Injected into NOD/SCID/IL2R $\gamma$ null mice. Stem Cells Int. 2011, 1-13. [CrossRef]

21. D'amico, M.A.; Ghinassi, B.; Izzicupo, P.; di Ruscio, A.; di Baldassarre, A. IL-6 Activates PI3K and PKC Signaling and Determines Cardiac Differentiation in Rat Embryonic H9c2 Cells: IL-6 AND CARDIAC DIFFERENTIATION OF H9c2 CELLS. J. Cell. Physiol. 2016, 231, 576-586. [CrossRef] [PubMed]

22. Ghinassi, B.; D’Addazio, G.; Di Baldassarre, A.; Femminella, B.; Di Vincenzo, G.; Piattelli, M.; Gaggi, G.; Sinjari, B. Immunohistochemical Results of Soft Tissues around a New Implant Healing-Abutment Surface: A Human Study. J. Clin. Med. 2020, 9, 9. [CrossRef] [PubMed]

23. Moore, L.D.; Le, T.; Fan, G. DNA methylation and its basic function. Neuropsychopharmacol. Off. Publ. Am. Coll. Neuropsychopharmacol. 2013, 38, 23-38. [CrossRef] [PubMed] 
24. Kashyap, V.; Rezende, N.C.; Scotland, K.B.; Shaffer, S.M.; Persson, J.L.; Gudas, L.J.; Mongan, N.P. Regulation of Stem Cell Pluripotency and Differentiation Involves a Mutual Regulatory Circuit of the Nanog, OCT4, and SOX2 Pluripotency Transcription Factors With Polycomb Repressive Complexes and Stem Cell microRNAs. Stem Cells Dev. 2009, 18, 1093-1108. [CrossRef] [PubMed]

25. Fraser, L.; Taylor, A.H.; Forrester, L.M. SCF/KIT Inhibition Has a Cumulative but Reversible Effect on the Self-Renewal of Embryonic Stem Cells and on the Survival of Differentiating Cells. Cell. Reprogramming 2013, 15, 259-268. [CrossRef]

26. Migliaccio, A.R.; Martelli, F.; Verrucci, M.; Sanchez, M.; Valeri, M.; Migliaccio, G.; Vannucchi, A.M.; Zigariello, M.; Di Baldassarre, A.; Ghinassi, B.; et al. Gata1 expression driven by the alternative HS2 enhancer in the spleen rescues the hematopoietic failure induced by the hypomorphic Gatallow mutation. Blood 2009, 114, 2107-2120. [CrossRef]

27. Martelli, F.; Ghinassi, B.; Lorenzini, R.; Vannucchi, A.M.; Rana, R.A.; Nishikawa, M.; Partamian, S.; Migliaccio, G.; Migliaccio, A.R. Thrombopoietin Inhibits Murine Mast Cell Differentiation. Stem Cells 2008, 26, 912-919. [CrossRef]

28. Nishino, K.; Toyoda, M.; Yamazaki-Inoue, M.; Fukawatase, Y.; Chikazawa, E.; Sakaguchi, H.; Akutsu, H.; Umezawa, A. DNA Methylation Dynamics in Human Induced Pluripotent Stem Cells over Time. PLoS Genet. 2011, 7, e1002085. [CrossRef]

29. Tesarova, L.; Simara, P.; Stejskal, S.; Koutna, I. The Aberrant DNA Methylation Profile of Human Induced Pluripotent Stem Cells Is Connected to the Reprogramming Process and Is Normalized During In Vitro Culture. PLoS ONE 2016, 11, e0157974. [CrossRef]

30. Göhring, A.R.; Reuter, S.; Clement, J.H.; Cheng, X.; Theobald, J.; Wölfl, S.; Mrowka, R. Human microRNA-299-3p decreases invasive behavior of cancer cells by downregulation of Oct4 expression and causes apoptosis. PLoS ONE 2017, 12, e0174912. [CrossRef]

31. Xu, N.; Papagiannakopoulos, T.; Pan, G.; Thomson, J.A.; Kosik, K.S. MicroRNA-145 Regulates OCT4, SOX2, and KLF4 and Represses Pluripotency in Human Embryonic Stem Cells. Cell 2009, 137, 647-658. [CrossRef] [PubMed]

32. Xu, D.; Zhou, P.; Wang, Y.; Zhang, Y.; Zhang, R.; Zhang, L.; Chen, S.; Fu, W.; Ruan, B.; Xu, H.; et al. miR-150 Suppresses the Proliferation and Tumorigenicity of Leukemia Stem Cells by Targeting the Nanog Signaling Pathway. Front. Pharmacol. 2016, 7. [CrossRef] [PubMed]

33. Zhou, X.; Yue, Y.; Wang, R.; Gong, B.; Duan, Z. MicroRNA-145 inhibits tumorigenesis and invasion of cervical cancer stem cells. Int. J. Oncol. 2017, 50, 853-862. [CrossRef]

34. Marion, R.M.; Strati, K.; Li, H.; Tejera, A.; Schoeftner, S.; Ortega, S.; Serrano, M.; Blasco, M.A. Telomeres Acquire Embryonic Stem Cell Characteristics in Induced Pluripotent Stem Cells. Cell Stem Cell 2009, 4, 141-154. [CrossRef] [PubMed]

35. Shyh-Chang, N.; Daley, G.Q.; Cantley, L.C. Stem cell metabolism in tissue development and aging. Development 2013, 140, 2535-2547. [CrossRef] [PubMed]

36. Roy, I.M.; Biswas, A.; Verfaillie, C.; Khurana, S. Energy Producing Metabolic Pathways in Functional Regulation of the Hematopoietic Stem Cells: HSC PROLIFERATION, AGEING. IUBMB Life 2018, 70, 612-624. [CrossRef] [PubMed]

37. Volarevic, V.; Markovic, B.S.; Gazdic, M.; Volarevic, A.; Jovicic, N.; Arsenijevic, N.; Armstrong, L.; Djonov, V.; Lako, M.; Stojkovic, M. Ethical and Safety Issues of Stem Cell-Based Therapy. Int. J. Med. Sci. 2018, 15, $36-45$. [CrossRef]

38. Toda, A.; Okabe, M.; Yoshida, T.; Nikaido, T. The Potential of Amniotic Membrane/Amnion-Derived Cells for Regeneration of Various Tissues. J. Pharmacol. Sci. 2007, 105, 215-228. [CrossRef]

39. Merrill, B.J. Wnt Pathway Regulation of Embryonic Stem Cell Self-Renewal. Cold Spring Harb. Perspect. Biol. 2012, 4, a007971. [CrossRef]

40. Boyer, L.A.; Lee, T.I.; Cole, M.F.; Johnstone, S.E.; Levine, S.S.; Zucker, J.P.; Guenther, M.G.; Kumar, R.M.; Murray, H.L.; Jenner, R.G.; et al. Core Transcriptional Regulatory Circuitry in Human Embryonic Stem Cells. Cell 2005, 122, 947-956. [CrossRef]

41. Kopp, J.L.; Ormsbee, B.D.; Desler, M.; Rizzino, A. Small Increases in the Level of Sox2 Trigger the Differentiation of Mouse Embryonic Stem Cells. Stem Cells 2008, 26, 903-911. [CrossRef] [PubMed] 
42. Chambers, I.; Silva, J.; Colby, D.; Nichols, J.; Nijmeijer, B.; Robertson, M.; Vrana, J.; Jones, K.; Grotewold, L.; Smith, A. Nanog safeguards pluripotency and mediates germline development. Nature 2007, 450, 1230-1234. [CrossRef] [PubMed]

43. Perumal, D.; Pillai, S.; Nguyen, J.; Schaal, C.; Coppola, D.; Chellappan, S.P. Nicotinic acetylcholine receptors induce c-Kit ligand/Stem Cell Factor and promote stemness in an ARRB1/ $\beta$-arrestin-1 dependent manner in NSCLC. Oncotarget 2014, 5. [CrossRef]

44. Pfeifer, G.P. Defining Driver DNA Methylation Changes in Human Cancer. Int. J. Mol. Sci. 2018, $19,1166$. [CrossRef] [PubMed]

45. Bilic, J.; Belmonte, J.C.I. Concise Review: Induced Pluripotent Stem Cells Versus Embryonic Stem Cells: Close Enough or Yet Too Far Apart? Stem Cells 2012, 30, 33-41. [CrossRef]

46. Suelves, M.; Carrió, E.; Núñez-Álvarez, Y.; Peinado, M.A. DNA methylation dynamics in cellular commitment and differentiation. Brief. Funct. Genom. 2016, 15, 443-453. [CrossRef] [PubMed]

47. van Schaijik, B.; Davis, P.F.; Wickremesekera, A.C.; Tan, S.T.; Itinteang, T. Subcellular localisation of the stem cell markers OCT4, SOX2, NANOG, KLF4 and c-MYC in cancer: A review. J. Clin. Pathol. 2018, 71, 88-91. [CrossRef]

48. Jeong, C.-H.; Cho, Y.-Y.; Kim, M.-O.; Kim, S.-H.; Cho, E.-J.; Lee, S.-Y.; Jeon, Y.-J.; Yeong Lee, K.; Yao, K.; Keum, Y.-S.; et al. Phosphorylation of Sox2 Cooperates in Reprogramming to Pluripotent Stem Cells. Stem Cells 2010, 28, 2141-2150. [CrossRef]

49. Huang, J.; Wang, F.; Okuka, M.; Liu, N.; Ji, G.; Ye, X.; Zuo, B.; Li, M.; Liang, P.; Ge, W.W.; et al. Association of telomere length with authentic pluripotency of ES/iPS cells. Cell Res. 2011, 21, 779-792. [CrossRef]

50. Wang, H.; Zhang, K.; Liu, Y.; Fu, Y.; Gao, S.; Gong, P.; Wang, H.; Zhou, Z.; Zeng, M.; Wu, Z.; et al. Telomere heterogeneity linked to metabolism and pluripotency state revealed by simultaneous analysis of telomere length and RNA-seq in the same human embryonic stem cell. BMC Biol. 2017, 15. [CrossRef]

51. Motedayyen, H.; Esmaeil, N.; Tajik, N.; Khadem, F.; Ghotloo, S.; Khani, B.; Rezaei, A. Method and key points for isolation of human amniotic epithelial cells with high yield, viability and purity. BMC Res. Notes 2017, 10. [CrossRef] [PubMed]

52. Falone, S.; Mirabilio, A.; Passerini, A.; Izzicupo, P.; Cacchio, M.; Gallina, S.; Baldassarre, A.D.; Amicarelli, F. Aerobic Performance and Antioxidant Protection in Runners. Int. J. Sports Med. 2009, 30, 782-788. [CrossRef] [PubMed] 